\title{
Le Droit et les Paradoxes de l'Universalité
}

DANIĖLE LOCHAK, PRESSES UNIVERSITAIRES DE FRANCE, PARIS, 2010

Noyelle Neumann das Neves*

A questão da universalidade está constantemente presente no debate relativo aos direitos humanos, ocupando nele um lugar central. A obra O Direito e os Paradoxos da Universalidade, da autora francesa Danièle Lochak-professora emérita de Direito Público da Universidade de Paris $\mathrm{X}$ e autora de diversas publicações na área dos direitos humanos - insere-se em um contexto de crítica, quando, na França, os debates sobre a "integração nacional" (que têm levantado polêmicas sobre temas como a laicidade, fazendo alusão às bases do próprio modelo republicano) têm colocado em evidência o uso ideológico e político que se tem feito dessa noção.

O objetivo da autora nesse livro é realizar uma releitura da noção de universalidade à luz do Direito, pois, segundo ela, este realça as tensões e os paradoxos que atravessam aquela noção tão complexa, repleta de ideologia e polêmica. Para abordar tal problemática, o livro está dividido em cinco capítulos. A própria autora afirmou, durante uma conferência de apresentação da obra em questão(1) , que o primeiro capítulo pode ser visto como um capítulo preliminar, um prólogo, e os quatro restantes desenvolvem as principais ideias objeto de seu trabalho.

A presente resenha buscará apresentar os argumentos desenvolvidos pela autora, fazendo uma análise de sua pertinência e importância e mostrando que tal discussão é relevante, também, no campo da saúde.

(*) Doutoranda em Direito Público e Mestre em Direitos Humanos, Universidade de Paris X; Especialista em Sociologia Política, Universidade Federal do Paraná. Advogada. Paris-França. E-mail: <noyelle @ gmail.com>.

Recebida em 16.06.11

(1) Conferência realizada na Universidade de Paris X, Nanterre, em data de 22 de março de 2011. 


\section{APREENDER A UNIVERSALIDADE}

A autora inicia seu estudo, nesse primeiro capítulo "preliminar", com uma identificação aprofundada da noção multiforme de universalidade. Partindo de suas definições lexicais, aborda, em seguida, o contexto histórico, político, religioso e cultural no qual a ideia emergiu, tornou-se dominante na Europa e, posteriormente, alvo de críticas convergentes. Com efeito, após uma análise lexical e semântica, a autora constata que a universalidade não é uma noção neutra, mas implicitamente valorada e potencialmente polêmica. Essa valorização resulta de uma visão (ocidental) de mundo: a importância adquirida por esse conceito é reflexo de ideias e crenças que caminharam desde a Antiguidade grega até tornarem-se dominantes na Europa, na época Moderna, especialmente no campo da filosofia e da ciência. A universalidade será, no entanto, constantemente alvo de críticas, especialmente na era da pós-modernidade.

Por fim, a autora apresenta as formas de emergência da universalidade no campo jurídico, mostrando como sua valorização passou do campo das ideias ao do Direito, e suas repercussões. De fato, a multiplicidade do uso da palavra "universal" e de suas consequências é um aspecto do domínio jurídico; no entanto, após uma análise aprofundada do direito positivo, é possível perceber que, se por um lado conotações positivas são associadas a essa ideia (o que explica em parte seu sucesso), por outro, não existe um conceito unitário e inequívoco dessa noção: os sentidos atribuídos aos termos empregados no vocabulário jurídico são não somente extremamente diversos entre si, mas também diferentes daqueles empregados no léxico geral. A centralidade da noção de universal não se situa, portanto, no direito positivo: é no valor acordado à universalidade da norma jurídica - geral, abstrata e impessoal -, apresentada como condição da universalidade dos direitos e diretamente ligada às premissas da Revolução Francesa, que reside sua importância. Quando tal termo é inserido no texto de uma lei, não se busca uma qualificação rigorosa, mas uma conotação valorizante que a ela é atribuída.

Atualmente, em um contexto de globalização, é importante fazer uma distinção entre universalismo jurídico (que questiona o caráter essencialmente nacional e estatal do Direito) e universalidade. No contexto atual existe uma pretensão de universal, uma tendência à uniformização, o que é diferente de um progresso da noção de universalidade: é o que a autora chama de uma universalidade "de fachada" ou fictícia.

\section{QUAL UNIVERSALIDADE PARA QUAL IGUALDADE?}

O valor acordado à universalidade da norma jurídica, apresentada como a condição da universalidade dos direitos, reflete uma tradição ideológica herdada da Revolução Francesa, que conduziu a uma forma abstrata de universalidade. Para 
os revolucionários, os direitos humanos são inerentes à natureza humana, natureza essa que é concebida abstratamente e é comum a todos os indivíduos concretos; estes devem, portanto, gozar de direitos iguais. Esse universalismo abstrato, que implicará que a regra jurídica seja "cega às diferenças", aparece como a garantia da igualdade de todos diante da lei, por meio da supressão dos privilégios.

A universalidade encontrará aqui seus limites, pois a igualdade jurídica deixa intactas as desigualdades de fato, podendo até mesmo agravá-las. Assim, a universalidade da regra - quase sempre confundida com sua uniformidade - não é suficiente para assegurar uma igualdade efetiva. A aplicação indiferenciada de uma mesma regra a todos gera uma falsa universalidade da norma e causa a perenização das desigualdades materiais, uma vez que os indivíduos são considerados de forma abstrata e não segundo suas particularidades.

O ideal da regra abstrata e uniforme cede, portanto, perante uma concepção mais exigente de igualdade, que pretende ultrapassar a simples igualdade formal para se aproximar de uma igualdade de condições. O legislador se servirá, portanto, do Direito para tentar compensar ou corrigir as desigualdades sociais, levando em consideração as diferenças de condição e de recursos, de idade, de sexo, até mesmo de origem: a lei não é mais a mesma para todos. Para promover a universalidade efetiva dos direitos, é preciso lidar com a universalidade abstrata da regra de direito: aos imperativos contraditórios da igualdade, oscilando entre a igualdade jurídica e a igualdade real, opõe-se a ambivalência do ideal universalista. Para atingi-lo deve-se tanto transcender as diferenças como modelar as leis de acordo com elas e, para isso, é preciso, muitas vezes, designar aqueles que se quer proteger, devendo-se, assim, romper, de forma mais ou menos manifesta, com a fórmula universalista da regra.

Para garantir o "direito à indiferença" (afirmação do direito absoluto de todo indivíduo de ser tratado como um ser humano, apesar de suas diferenças, princípio fundamental protetor contra as discriminações), ou seja, para proibir e reprimir a consideração ilegítima das diferenças na aplicação da lei, é preciso começar pela designação daqueles a quem se quer acordar uma aplicação específica, oficializando, portanto, tais diferenças conferindo-lhes uma existência jurídica. No entanto, a designação de grupos vulneráveis, que leva à aplicação de um regime de proteção específica, não ocorre sem paradoxos nem dificuldades. Conforme a jurisprudência da Corte Suprema dos Estados Unidos, considera-se como "suspeita" toda discriminação que visa a um grupo caracterizado pela imutabilidade de seus traços constitutivos e que foi tradicionalmente vítima de hostilidades e prejuízos.

O princípio da igualdade se transforma, então, em um princípio de não discriminação: o que ele proíbe não é mais a diferença de tratamento, mas a diferença injustificada, qualificada de discriminatória. A necessidade de levar em conta certas formas de vulnerabilidade pode encorajar os Estados a adotarem medidas "especiais", temporárias (pois são consideradas como medidas de recuperação), em favor de grupos tradicionalmente vítimas de discriminação: 
trata-se da implementação de "ações positivas" ou "ações afirmativas" para prevenir ou compensar as desvantagens ligadas à raça, origem étnica, religião, idade, deficiência ou orientação sexual.

Dessa forma, transigir a universalidade formal da regra de Direito é inevitável para assegurar a universalidade de direitos. Todavia, as controvérsias suscitadas pela questão da paridade, a polêmica em torno das discriminações positivas ou das estatísticas étnicas mostram até que ponto as exigências da igualdade são paradoxais e o ideal da universalidade ambivalente.

\section{A UNIVERSALIDADE À PROVA DAS IDENTIDADES MINORITÁRIAS}

O universalismo abstrato implica que o Direito seja indiferente não somente diante das características individuais, mas também diante do pertencimento a um dado grupo particular - religioso, linguístico, étnico etc. Como já mencionado, a aplicação das mesmas regras a todos, sem levar em conta tais identidades, foi concebida como um princípio protetor contra as discriminações. No entanto, também esse princípio, se levado ao pé da letra, pode acabar por impossibilitar os grupos minoritários de exercer na prática seus direitos fundamentais, teoricamente reconhecidos sob uma base universal. Existe um momento no qual, para respeitar em cada indivíduo sua parcela de alteridade, o Direito deve levar em conta as diferenças, as constituições identitárias individuais e até mesmo dar lugar às identidades coletivas. Essa exigência levará, muitas vezes, ao reconhecimento de direitos específicos aos membros de grupos minoritários, não de uma forma temporária, como no caso das ações afirmativas, mas de forma permanente. Mesmo em um país como a França, que recusa o reconhecimento de uma existência oficial às minorias, o Direito é obrigado a se adaptar para responder às exigências da liberdade de pensamento ou às reivindicações das populações dos departamentos ultramarinos. É preciso, portanto, diferenciar o que se trata de uma luta contra a discriminação (medidas temporárias) e o que se trata de uma gestão das diferenças.

As politicas de gestão das diferenças são variáveis em função das tradições nacionais, do contexto político de evolução das sociedades e das ideias. Além da diversidade de modelos, encontra-se em todo lugar a tensão entre o "direito à indiferença" e o "direito à diferença" (o direito de ter sua diferença reconhecida em nome do respeito à diversidade humana).

A questão das identidades coletivas era tratada com base no esquema clássico da proteção das minorias, que inspira ainda hoje o tratamento e o reconhecimento de direitos aos povos indígenas. Porém, tal esquema foi atualmente englobado pela problemática dos direitos culturais, que visa protegê-las além da simples questão das minorias: tal enfoque pretende escapar das contradições inerentes à noção de minoria. $\mathrm{O}$ destaque dado à diversidade cultural converge 
com as teses multiculturalistas, que propõem a valorização e consideração, no espaço público, da identidade cultural, étnica ou religiosa.

De fato, o multiculturalismo retrata o pluralismo das sociedades contemporâneas, caracterizadas pela existência, em seus seios, de grupos muito diferentes, que reivindicam a conservação de sua identidade e maior visibilidade e representação no espaço público. A diversidade do termo vai muito além da concepção estrita de "cultura" e engloba diferentes formas de identidades: minorias étnicas, religiosas, regionais, mas também o gênero e a orientação sexual. Trata-se de um modo de gestão das diferenças que se desenvolveu no final dos anos 1960 em diversas democracias ocidentais, em resposta à mobilização de grupos minoritários. O termo expandiu-se nos anos 1980, especialmente nos países anglo-saxões, e foi teorizado como um novo modelo de governo das sociedades pluralistas. Assim, o multiculturalismo pretende realizar a articulação democrática entre dois princípios de difícil conciliação: o reconhecimento das particularidades culturais e o respeito de valores universais, apostando na possibilidade de escapar ao dilema da escolha entre universalismo abstrato e "comunitarismo".

$\mathrm{Na}$ cena internacional, da mesma forma, as reivindicações identitárias apresentadas pelos grupos minoritários e os povos indígenas enfrentam a resistência dos Estados, pouco inclinados a introduzir em seus seios os fermentos para um pluralismo, percebido como ameaçador; tal reticência contradiz o postulado da universalidade dos direitos humanos. Assim, nas sociedades multiculturais contemporâneas - caracterizadas pela coexistência de grupos de origens diversas, que contribuem para forjar as identidades individuais e/ ou coletivas - a consideração da diversidade aparece, em certos casos, como uma condição para garantir aos membros de um grupo, na maioria das vezes marginalizados, um exercício efetivo dos direitos universais, e não somente um acesso teórico.

\section{UNIVERSALIDADE DOS DIREITOS HUMANOS: EVIDÊNCIA OU MITO?}

O respeito das particularidades culturais é um argumento igualmente apresentado para relativizar a universalidade dos direitos humanos ou para denunciar sua universalidade de fachada: como defender que tais direitos, que são uma invenção do Ocidente, valem necessariamente para todas as culturas? Além de sua dimensão teórica, essa interrogação leva a uma constatação de natureza ideológica e política.

A universalidade dos direitos humanos era natural aos olhos daqueles que os proclamaram, pela primeira vez em 1789 e, novamente, em 1948. Ambas as declarações postularam a universalidade, mas, de uma à outra, o fundamento de tal demanda se alterou: sua significação transformou-se e expandiu-se com a inclusão da ideia de indivisibilidade dos direitos civis e políticos e dos direitos 
sociais, econômicos e culturais, vista como a condição da universalidade efetiva de todos os direitos. Conforme as expectativas, a reivindicação dos direitos humanos se difundiu em todo o planeta. Porém, tal universalidade é minada pela negação constante a que tais direitos são submetidos no campo prático, o que mostra que sua aplicação está longe de ser universal.

Apesar da recusa em estabelecer qualquer hierarquia entre os direitos humanos, os direitos sociais (ou de segunda geração) não conseguem ultrapassar o déficit de legitimidade e de "justiciabilidade"(2). A elaboração de dois Pactos distintos, em 1966, no momento em que se passava de um sistema declaratório a um sistema convencional, representa, sob esse ponto de vista, uma regressão e uma fragilização da indivisibilidade dos direitos humanos. Na prática, a questão da universalidade não se põe exatamente nos mesmos termos e não levanta os mesmos tipos de contestações ou de objeções para essas duas categorias de direitos. A universalidade dos direitos civis e políticos é eventualmente contestada em nome do relativismo cultural; a dos direitos sociais, por sua vez, encontra seus principais limites no momento de sua concretização. Enquanto os direitos civis e políticos são imediata e diretamente aplicáveis, os direitos econômicos, sociais e culturais veem sua realização subordinada a uma melhora progressiva dos recursos públicos. Tal cláusula de progressividade incita os Estados a se considerarem como desvinculados de qualquer obrigação quanto a esses direitos.

Ademais, a internacionalização dos direitos humanos é, ao mesmo tempo, sinal de sua universalidade e vetor de sua universalização. Porém, sua difusão planetária não é uma garantia de sua universalidade: é preciso que ela seja objeto de uma adesão compartilhada e não da imposição de uma concepção puramente ocidental. Daí a grande dificuldade em conciliar a universalidade dos direitos humanos com a preservação das identidades culturais, reconhecida ela mesma como um direito fundamental.

Ao mesmo tempo, a comunidade internacional mostra-se impotente para impedir as violações massivas de direitos humanos que continuam a ser perpetradas em diversas partes do mundo. $O$ respeito aos direitos humanos vincula os Estados, pois tais direitos são objeto de convenções internacionais ratificadas pela quase totalidade deles. Porém, não existe um mecanismo contencioso que permita garantir o respeito dessas obrigações: os direitos humanos são, no mundo inteiro, quotidianamente violados, e até mesmo expressamente desrespeitados pelas autoridades estatais. Apesar de todas as declarações que proclamam solenemente a obrigação dos Estados, a soberania nacional resta hoje um dos maiores obstáculos à universalidade dos direitos humanos. Tantos outros elementos conduzem à constatação de que a universalidade dos direitos humanos tropeça sempre na existência de Estados soberanos que visam defender suas prerrogativas.

(2) Justiciabilité em francês, termo que indica a possibilidade de invocar um direito diretamente perante um juiz. 
O último ponto abordado pela autora quanto à controvertida universalidade dos direitos humanos é a questão de que os direitos proclamados como universais são somente parcialmente reconhecidos aos imigrantes estrangeiros. Com efeito, historicamente a noção de direitos fundamentais, em si favorável aos estrangeiros (pois, em sua origem são direitos que não dependem da cidadania, da fé ou da ação do Estado, ou seja, são direitos naturais), foi entravada pela ascensão dos Estados-nação e o reforço da soberania estatal, o que reduziu o acesso a tais direitos somente aos nacionais. Pode-se, portanto, afirmar que existe uma contradição entre a universalidade dos direitos humanos e a afirmação da soberania nacional, e a condição dos imigrantes confirma globalmente essa análise. Diante dessa problemática, pode-se questionar se tais direitos seriam universais ou apenas "nacionais".

A autora afirma que não se deve confundir a questão teórica da visão universal dos direitos humanos com a questão empírica de sua aplicação universal, pois não se pode julgar a validade de um princípio à luz de sua efetividade. No entanto, como o ideal é a tal ponto contrariado pelos fatos, torna-se razoável considerar mística a pretensão dos direitos humanos à universalidade.

\section{RESSURGIMENTO DA HUMANIDADE COMO SÍMBOLO DO UNIVERSAL}

A humanidade traz em si mesma a dimensão do universal. A universalidade, traduzindo uma visão de mundo, remete à ideia de uma unidade da humanidade e funda a própria noção de direitos humanos. A emergência do conceito de humanidade no âmbito do direito internacional é importante, na medida em que ela é o sinal de uma aspiração de construir um universal planetário transcendendo as comunidades estatais. Tal aspiração manifesta-se na tarefa que foi atribuída à comunidade internacional de punir os "crimes contra a humanidade", estabelecendo jurisdições penais internacionais ou prevendo uma "competência universal" dos Estados para julgar os autores desses crimes, em nome da humanidade. Pode-se percebê-la, também, nas mobilizações para o reconhecimento de um direito de intervenção humanitária ou no surgimento da ideia de uma "responsabilidade de proteger".

De fato, é com a aparição da noção de crimes contra a humanidade que esta se torna verdadeiramente uma categoria jurídica; ela faz sua entrada no Direito, portanto, como vítima. Além dessa incriminação particular, o desenvolvimento posterior de um Direito Penal Internacional - com a criação de Tribunais Penais Internacionais ou, de forma mais significativa ainda, por meio do mecanismo da competência universal - pode ser lido como a implementação da obrigação que pesa sobre a comunidade de Estados de punir os autores de crimes internacionais: aqueles crimes que, em razão de sua natureza e gravidade, atentam contra, e portanto concernem, a humanidade inteira. O conceito, mais recente ainda, de responsabilidade de proteger, traduz também a obrigação 
solidária que pesa sobre a comunidade internacional de impedir as violações massivas de direitos humanos ou do Direito Humanitário, pois, onde quer que elas ocorram, é a humanidade inteira que está em causa.

Por fim, o ressurgimento da humanidade como símbolo do universal se exprime também por uma tomada de consciência da vulnerabilidade do planeta e da solidariedade do destino que une o conjunto dos habitantes. Ela reflete-se em noções como "patrimônio comum da humanidade" ou "bens públicos mundiais" e encontra sua tradução em inúmeros instrumentos internacionais. Com efeito, o papel crescente ocupado pelo conceito de humanidade, com as implicações normativas que a ele são relacionadas, é ligado em parte à emergência de uma "ideologia solidarista" derivada da consciência de uma interdependência de fato entre os Estados e os povos, e das ameaças ambientais e ecológicas em escala planetária.

Porém, essas evoluções - que podem ser interpretadas como um passo para a construção de um "Direito cosmopolita", que, livre de Estados, uniria diretamente os indivíduos à humanidade - encontram seus limites na resistência do modelo tradicional de uma sociedade internacional fundada na coexistência igualitária de Estados soberanos. De fato, a teoria do Direito Internacional sempre oscilou entre dois ideais: o modelo de uma sociedade de Estados soberanos, com um Direito interestatal resultado de convenções estabelecidas entre eles; $\mathrm{e}$ o modelo da humanidade soberana, acompanhado do projeto de uma federação de Estados em escala mundial, na qual os sujeitos de direito são os indivíduos, não os Estados. Se o modelo interestatal é de longe o modelo dominante, ele é constantemente submetido à pressão do modelo da humanidade universal. Contudo, seria irrealista interpretar tais elementos como o sinal de uma passagem de um modelo a outro. Tal série de evoluções poderia, no entanto, ser interpretada como indícios de um Direito cosmopolita em gestação, indícios que não se destinariam a substituir o modelo interestatal, mas que influenciam o seu conteúdo.

\section{CONCLUSÃO: UMA UNIVERSALIDADE PARADOXAL}

A partir das ideias expostas em sua obra, a professora Danièle Lochak extrai da noção de universalidade quatro paradoxos:

a) O primeiro deles é inerente a uma visão de mundo que dá prioridade a uma visão unitária da humanidade que, apesar de postular pela possibilidade de enunciar normas universalmente válidas, não é universalmente compartilhada, pois é enraizada na história e na cultura ocidentais. As civilizações asiáticas não cultivaram essa noção, seja porque ela lhes parece incongruente (como é o caso do Japão, fixo ao seu destino único e à cultura do singular), seja, ao contrário, porque ela lhes era inútil (a China não possui qualquer necessidade de produzir 
um conceito universal para lhe reivindicar, uma vez que ela se autoapresenta não somente como sendo o centro do mundo, mas como sendo o próprio mundo). Tal contradição aparece quando se trata de direitos humanos: evidentemente, eles só podem ser pensados no modelo da universalidade, pois só têm sentido se forem válidos para todos; porém, tal evidência repousa sobre a valorização do universal abstrato, característica de uma tradição do pensamento ocidental. A pretensão dos direitos humanos à universalidade é, portanto, objeto de uma contestação vigorosa, em nome da diversidade cultural, por ser uma concepção que se recusa a levar em conta os contextos históricos e culturais, susceptíveis de influenciar a percepção de tais direitos.

b) Seguindo a crítica anterior, pode-se extrair o segundo paradoxo da universalidade: atingir o universal supõe transcender as diferenças, ultrapassar os pertencimentos singulares; porém, um universal construído com base na erradicação das identidades individuais ou coletivas não possui sentido nem interesse. Aqui se coloca a questão delicada da articulação entre o singular e o universal, pois existe certamente uma tensão entre a obrigação de tratar todos os seres humanos segundo critérios idênticos, de aplicar a todos as mesmas normas sob uma base universal e a necessidade de respeitar as identidades individuais e coletivas que conduzem ao reconhecimento de direitos específicos sob a base dos pertencimentos particulares.

Se se admitir que os homens não são somente cidadãos abstratos, mas sim indivíduos portadores de uma história e de uma cultura singulares, se se admitir que a possibilidade de escolher e de preservar sua identidade, o reconhecimento das identidades culturais não significa o abandono do ideal universalista. Tal noção dá prioridade a uma outra concepção de universalidade, atenta às necessidades e aspirações dos grupos minoritários, e propõe uma outra forma de construir o universal, a partir da aceitação das diferenças, e não de sua negação.

c) O terceiro paradoxo é aquele de um conceito que supõe uma forma de abstração quanto à realidade empírica, mas que essa mesma abstração corre o risco de perder seu objetivo: o gozo concreto por todos dos direitos proclamados como universais. A concepção abstrata de universalidade, herdada do pensamento filosófico e científico, propagou-se no campo jurídico por meio da referência ao direito natural antes de penetrar no direito positivo. São universais os princípios ou as regras que valem para todos os indivíduos, para todos os seres humanos, independentemente do que os diferencia uns dos outros e que, por essa razão, só podem ser formulados de maneira abstrata.

Porém, essa universalidade abstrata, implicitamente valorizada e até mesmo explicitamente erigida em dogma, encontra seus próprios limites em seu próprio projeto de assegurar a todos os mesmos direitos sob uma base de igualdade. Pois, para que essa igualdade seja efetiva, e não somente teórica, é necessário levar em conta as diferenças que existem na realidade, renunciar 
à uniformidade de uma mesma lei para todos. Transigindo com o ideal de uma universalidade abstrata, não se renuncia, no entanto, a toda ambição universalista: o que se busca é o contrário, assegurando uma igualdade real, dar à universalidade um conteúdo concreto.

d) Um quarto paradoxo constatado é a ideia segundo a qual os avanços normativos do direito internacional, que traduzem a emergência de uma forma de cosmopolis, transcendendo as comunidades estatais, não podem se concretizar, sem a ajuda dos Estados. A tensão entre os germes de um "direito cosmopolita" e a realidade de uma sociedade internacional composta de Estados soberanos atravessa o Direito Internacional. Os conceitos de jus cogens, de crime contra a humanidade, de responsabilidade de proteger ou ainda o mecanismo da competência universal traduzem a vontade de agir da comunidade internacional diante das graves violações de direitos humanos cometidas pelos Estados sob o abrigo de sua soberania, já que tais violações são consideradas como desrespeito aos direitos da humanidade como tal. Mas, a humanidade não possui existência institucional, de modo que os processos implementados supõem a colaboração dos Estados, que podem, portanto, na prática, entravar sua efetividade.

Da mesma forma, a referência ao "patrimônio comum da humanidade", expressão simbólica entre outras, ou a preocupação de preservar o meio ambiente, reafirmada regularmente quando das conferências internacionais, traduz um sentimento de pertencimento a uma mesma humanidade cujos membros estão ligados por uma solidariedade de destino. Mas, na ausência de uma autoridade legítima para definir os interesses da humanidade, cabe aos Estados ou aos seus representantes nas organizações internacionais falar em nome dela - Estados esses que são reticentes a renunciar às suas próprias prerrogativas para o bem dessa mesma humanidade e a sacrificar seus próprios interesses imediatos para garantir o das gerações futuras.

A conclusão da autora é, portanto, pela existência de uma universalidade paradoxal e que tais paradoxos são refletidos pelo Direito. Além das incertezas e incoerências da legislação que deles resultam, é a questão dos direitos que se põe, pois o derradeiro desafio da aspiração que subentende a ideia de universalidade são os direitos humanos. Ela reforça o abismo entre o ideal e a realidade, o contraste entre a proclamação solene de direitos universais do Homem, colocados sob a proteção da comunidade internacional, e a situação real dos direitos humanos no mundo.

Porém, as desigualdades na possibilidade efetiva de exercer esses direitos proclamados como universais são impressionantes: desigualdades ligadas ao sexo, ao pertencimento a um grupo minoritário ou marginalizado, ao status de estrangeiro e, mais ainda, à condição de migrante; sobretudo, as desigualdades relacionadas ao local do mundo em que se teve a sorte ou o azar de nascer. $\mathrm{O}$ abismo entre o Norte e o Sul é, sob esse ponto de vista, o símbolo manifesto 
da derrota em liberar os povos "do terror e da miséria". Mas, nesse contexto, a afirmação da universalidade dos direitos humanos como perspectiva para a humanidade se torna ainda mais essencial.

Com efeito, as reflexões trazidas em O Direito e os Paradoxos da Universalidade contribuem para uma melhor apreensão da problemática envolvendo os direitos humanos, direitos das minorias e a universalidade. Elas servem de alerta aos problemas que surgem para um respeito dos direitos humanos de forma efetiva. Tais reflexões podem ser desenvolvidas, também, no campo da saúde: é possível perceber que as implicações da universalidade, e seus paradoxos, apresentadas na obra quanto aos direitos humanos em geral, possuem consequências também no domínio sanitário.

Podem-se observar alguns traços de tal relação, em primeiro lugar, no próprio direito à saúde, que, como direito fundamental, é um direito universal. Sem buscar apresentar uma lista exaustiva de tais implicações, podem-se extrair algumas do próprio artigo 196 da Constituição Federal brasileira: ao dispor que a saúde é "direito de todos e dever do Estado, garantido mediante políticas sociais e econômicas que visem à redução do risco de doença e de outros agravos e ao acesso universal e igualitário às ações e serviços para sua promoção, proteção e recuperação" (grifou-se), ele traz importantes pontos de intersecção. Ela deve ser garantida plenamente a todo cidadão, independentemente de qualquer fator pessoal ou coletivo. A universalidade é mesmo um dos princípios de regem o Sistema Único de Saúde brasileiro, que deve atender a todos, sem distinções ou restrições, oferecendo toda a atenção necessária, sem qualquer custo. Além disso, a lógica desse sistema vale para todos, na medida em que ele define responsabilidades e competências, que independem das particularidades dos contextos locais. Quando estipula que a saúde é um dever do Estado, entra-se no campo do acesso à saúde para todos, do exercício efetivo desse direito e dos entraves práticos quanto à efetividade dos direitos sociais, tanto no plano nacional como no internacional. Ademais, não se pode esquecer que a pessoa doente, por ser uma pessoa vulnerável, possui direitos específicos à sua condição de usuário do sistema de saúde. Por fim, uma particularidade do campo da saúde é a universalidade também do risco sanitário, risco este que implica uma universalização e complementaridade das práticas sanitárias nacionais e internacionais. Além das pandemias (como, por exemplo, a AIDS) ou das panzootias (como a gripe aviária), ocorre atualmente uma generalização das doenças e dos "flagelos" sociais (como o tabagismo, alcoolismo ou o uso de drogas). Devido à universalidade do risco sanitário, fala-se, hoje, de uma globalização/ universalização do direito da saúde, o que, segundo as lições trazidas por Danièle Lochak no livro analisado, não ocorrerá sem paradoxos nem contradições. 